\title{
FUNCTIONAL CHARACTERIZATION OF A SHARPENING OF THE TRIANGLE INEQUALITY
}

\author{
WŁODZIMIERZ FECHNER
}

Abstract. Motivated by recent refinements of the classical triangle inequality in normed spaces proved by Lech Maligranda we deal with related functional equation and inequality and with the corresponding stability problem.

Mathematics subject classification (2010): 39B62, 39B82, 46B20, 46B99.

Keywords and phrases: norm inequality, triangle inequality, functional equation, functional inequality, Hyers-Ulam stability.

\section{REFERENCES}

[1] J. ACZÉL, Lectures on functional equations and their applications, Academic Press, New York-San Francisco-London, 1966.

[2] T. AOKI, On the stability of the linear transformation in Banach spaces, J. Math. Soc. Japan, 2 (1950), 64-66.

[3] E. BerZ, Sublinear functions on R, Aequationes Math., 12, 2-3 (1975), 200-206.

[4] A. Chaljub-Simon, P. Volkmann, Caractérisation du module d'une fonction additive à l'aide d'une équation fonctionnelle, Aequationes Math., 47, 1 (1994), 60-68.

[5] Z. GAJDA, On stability of additive mappings, Internat. J. Math. Sci., 14, 3(1991), 431-434.

[6] R. Ger, Fischer-Muszély additivity on Abelian groups, Comment. Math. Prace Mat. (2004) Tomus Specialis in honorem Juliani Musielak, 82-96.

[7] D. H. Hyers, On the stability of the linear functional equation, Proc. Nat. Acad. Sci. U. S. A., 27 (1941), 222-224.

[8] L. Maligranda, Simple norm inequalities, Amer. Math. Monthly, 113 (2006), 256-260.

[9] L. Maligranda, Some remarks of the triangle inequality for norms, Banach J. Math. Anal., 2, 2 (2008), 31-41.

[10] L. Maligranda, A result of Tosio Aoki about a generalization of Hyers-Ulam stability of additive functions - a question of priority, Aequationes Math., 75, 3 (2008), 289-296.

[11] A. TARs Ki, Problem no. 83, Parametr 1 (1930), No. 6, 231; Solution: Młody Matematyk 1 (1931), No. 1, 90 (in Polish). 